\title{
Randomized comparative study to evaluate the role of proximal femoral nail and dynamic hip screw in unstable trochanteric fractures
}

\author{
Shivanand C. Mayi*, Sachin Shah, Sadashiv R. Jidgekar, Arunkumar Kulkarni
}

Department of Orthopedics, Khaja Bandanawaz Institute of Medical Sciences, Kalaburagi, Karnataka, India

Received: 21 July 2016

Accepted: 26 July 2016

*Correspondence:

Dr. Shivanand C Mayi,

E-mail: drshivanandmayi@gmail.com

Copyright: ( $\subset$ the author(s), publisher and licensee Medip Academy. This is an open-access article distributed under the terms of the Creative Commons Attribution Non-Commercial License, which permits unrestricted non-commercial use, distribution, and reproduction in any medium, provided the original work is properly cited.

\begin{abstract}
Background: Treatment of unstable trochanteric fracture is much more challenging than stable fracture. These fractures require stable fixation to minimize the fracture and implant related complications. Need of this study is to assess the suitable implant for stable fixation of unstable trochanteric fracture with less intra and postoperative complications and good functional outcome.

Methods: In this prospective randomized comparative study, 64 patients were distributed into two groups. Group A consisted of patients treated by proximal femoral nail $(\mathrm{PFN})(\mathrm{n}=32)$ and group B treated by dynamic hip screw (DHS) $(n=32)$. All the patients were evaluated preoperatively and surgery was done according to the group they were allotted. Post-operative follow up was done at 6 weeks, 3, 6 and 12 months.

Results: Average age of the patients in this study was $51.26 \pm 10.24$ year. In this study patients were followed up for an average of $10.87 \pm 2.61$ month. The duration of surgery was shorter in PFN group. Weight bearing was earlier in PFN group than DHS group. Mean functional ability score was better in PFN group with significant gain in function earlier as compared to DHS group.

Conclusions: PFN is a better implant for internal fixation of unstable trochanteric fractures which allows early mobilization and has got better functional outcome score in early postoperative period than DHS.
\end{abstract}

Keywords: Unstable trochanteric fracture, Proximal femoral nail, Dynamic hip screw

\section{INTRODUCTION}

The stability of the trochanteric fracture depends on the amount of contact between the proximal and distal main fragments. Trochanteric fractures with comminution of posteromedial buttress exceeding simple lesser trochanteric fragment or with subtrochanteric extension are termed as unstable. In 3-part fractures stability is inversely proportional to the size of the lesser trochanteric fragment. Instability occurs when more than $50 \%$ of the calcar is affected allowing the proximal fragment to collapse into varus with shortening. Reverse obliquity fracture is unstable fracture in which major fracture line extends outward and downward from the lesser trochanter.

Unstable trochanteric fractures are technically much more challenging than stable fractures. Stable reduction of an intertrochanteric fracture requires providing medial and posterior cortical contact between the major proximal and distal fragment to resist varus and posterior displacing forces. For unstable fractures intramedullary implants are (biomechanically) superior. ${ }^{1}$ Lag screw cut-out failure following fixation of unstable intertrochanteric fractures in osteoporotic bone remains an unsolved challenge. ${ }^{2}$ 
The double screw construct provides significantly greater resistance against varus collapse and neck rotation in comparison to a standard DHS lag screw implant. ${ }^{3}$ Less sliding of the femoral neck screws was noted with twofemoral neck screw configuration. ${ }^{2}$ This study was conducted to assess the suitable implant for stable fixation of unstable trochanteric fracture with less intra and postoperative complications and good functional outcome which should be the goal of every orthopaedic surgeon treating these fractures.

\section{METHODS}

Between October 2013 to July 2015, 64 patients with unstable trochanteric fracture were randomised into two groups to be treated with PFN or DHS. Institutional ethical committee was informed and clearance was taken for the study. All the patients admitted to our hospital in the age group of 20-60 years with fresh unstable trochanteric fracture willing to participate in the study were allotted to PFN or DHS group. Random allocation of the treatment modality was done after taking informed consent from the patients. Polytrauma patients, pathological fracture, patients who were not able to walk independently before the injury and patients who refused to give consent were excluded from the study.

After admission relevant blood investigations and plain radiographs of the both hips AP view and involved hip lateral view were taken. Fracture classification was done according to Arbeitsgemeinschaft für Osteosynthesefragen (AO) / Orthopaedic Trauma Association (OTA) classification. The type of treatment was according to randomized table in Microsoft Excel. Pre-operative data about the mode of injury and pre injury ambulatory status of the patient was collected. Patients were taken for surgery within 48 hours of admission after clearance from the anesthetist. All the patients were operated by same surgical team.

All the patients received preoperative antibiotics. Operation was done by standard approach using DHS and PFN. All surgeries were done under the guidance of image intensifier. Lateral approach was used for DHS (Figure 1). PFN was done by standard cephalomedullary approach through the modified medial trochanteric portal (Figure 2). ${ }^{4}$ Physiotherapy was started on first postoperative day. Partial weight bearing was started as and when patient is comfortable with walker support. Full weight bearing was allowed after radiological union of fracture and patient was free of pain. Follow up study included clinical examination with functional assessment according to Larson's hip evaluation chart 2 (higher the score better the functional outcome). 1st evaluation was carried out at 6 weeks postoperatively. Subsequent follow up evaluation was carried out at 3 months, 6 months and one year.
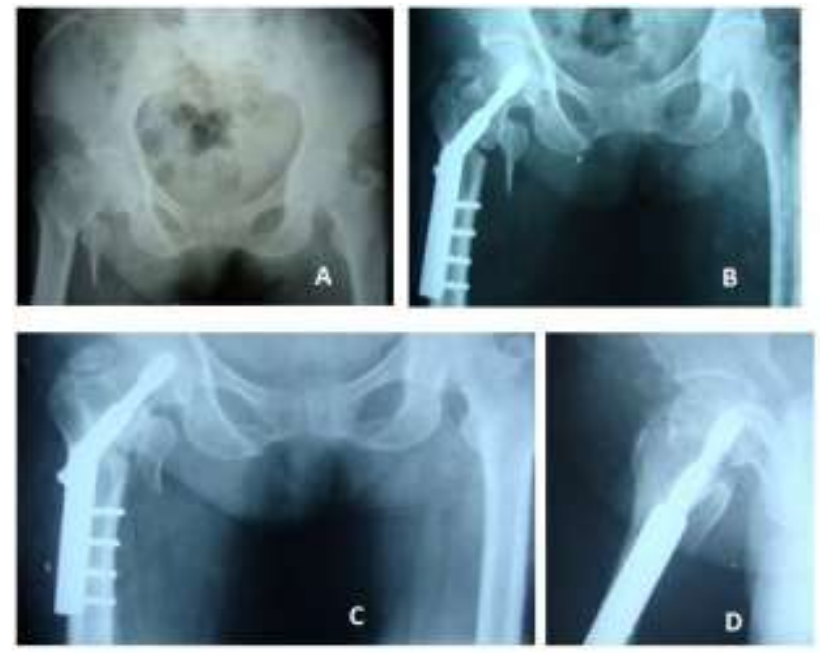

Figure 1: Patient treated by DHS. A) preoperative; B) postoperative; C) X-ray; D) follow up X-ray at 6 months.
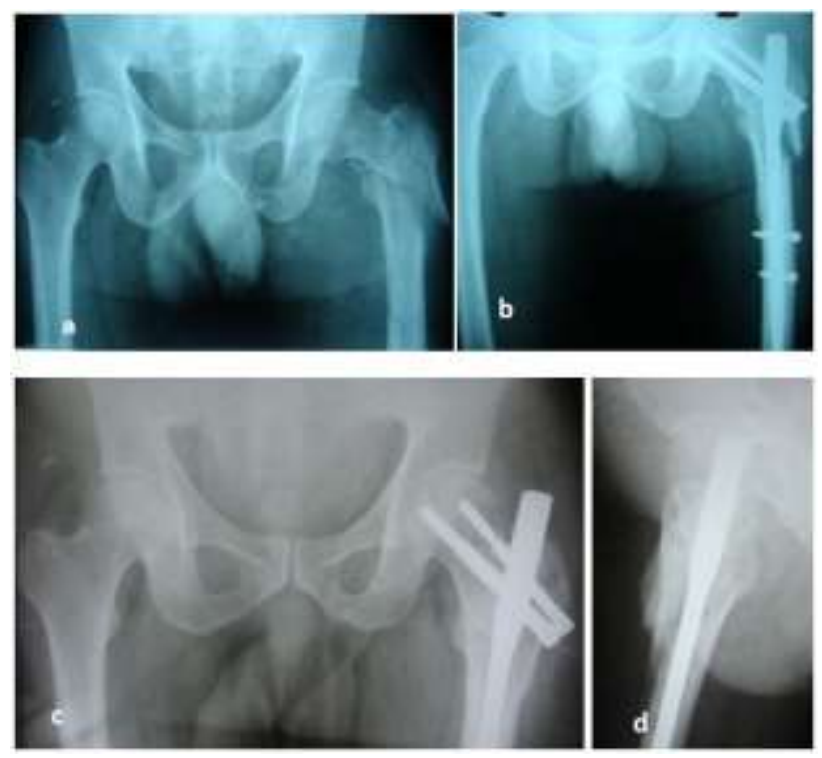

Figure 2: Patient treated by PFN. A) preoperative; B) postoperative; C) X-ray; D) follow up X-ray at 6 months.

\section{RESULTS}

In this randomized comparative study consisting 64 patients, DHS was used in 32 and PFN in other 32 patients. The average age of patients in this study was $51.26 \pm 10.24$ year (22-60 years). Other demographic data of the study individuals and fracture pattern are as given in Table 1. Follow up period ranged from 6 months to 18 months with an average of $10.87 \pm 2.61$ week. Patients in the age range from 20 years to 50 years had history of high velocity injury (RTA or fall from height) and most of the patients from 51 to 60 years age had history of low velocity injury (simple fall while walking) in this study. Predominant fracture type in this study was 32A2.3 (53.12\%) according to AO/OTA classification. 
Table 1: Demographic data of the patients.

\begin{tabular}{|llll|}
\hline Variables & Total $(\mathbf{n}=\mathbf{6 4})$ & PFN $(\mathbf{n = 3 2})$ & DHS (n=32) \\
\hline Mean age \pm SD & $73.84 \pm 8.75$ & $50.06 \pm 9.86$ & $52.46 \pm 10.61$ \\
\hline Sex of the patients & & \\
\hline Male & $49(76.56 \%)$ & $24(75 \%)$ & $25(78.12 \%)$ \\
\hline Female & $15(23.44 \%)$ & $08(25 \%)$ & $07(21.87 \%)$ \\
\hline Fractures operated & & $23(71.87 \%)$ \\
\hline Right side & $42(65.62 \%)$ & $19(59.37 \%)$ & $09(28.12 \%)$ \\
\hline Left side & $22(34.38 \%)$ & $13(40.62 \%)$ & $17(53.12 \%)$ \\
\hline Mode of injury & & $09(28.12 \%)$ \\
\hline Simple fall while walking & $26(40.62 \%)$ & $09(28.12 \%)$ & $04(12.5 \%)$ \\
\hline Road traffic accident & $23(35.93 \%)$ & $14(43.75 \%)$ & $02(6.25 \%)$ \\
\hline Fall from height & $13(20.31 \%)$ & $09(28.12 \%)$ & $09(28.12 \%)$ \\
\hline Fall of wall over patient & $02(3.12 \%)$ & $00(0 \%)$ & $17(53.12 \%)$ \\
\hline Fracture type (AO/OTA\#) & & $02(6.25 \%)$ \\
\hline 32A2.2 & & $08(32 \%)$ & $04(12.5 \%)$ \\
\hline 32A2.3 & $17(26.54 \%)$ & $17(53.12 \%)$ & $04(12.5 \%)$ \\
\hline 32A3.1 & $34(53.12 \%)$ & $03(9.37 \%)$ & \\
\hline 32A3.3 & $06(9.37 \%)$ & & \\
\hline \# & $07(10.93 \%)$ & & \\
\hline
\end{tabular}

\#Orthopedic trauma association

Table 2: Comparison of PFN with DHS.

\begin{tabular}{|llll|}
\hline & PFN $(\mathrm{n}=32)$ & DHS $(\mathrm{n}=31)$ & P value (Kruskal-Wallis test) \\
\hline Mean duration of surgery (minutes) & $60.25 \pm 10.24$ & $90.78 \pm 8.04$ & $\mathrm{P}<0.001^{*}$ \\
\hline $\begin{array}{l}\text { Mean duration after which patient started weight } \\
\text { bearing (weeks) }\end{array}$ & $4.96 \pm 1.63$ & $8.03 \pm 2.26$ & $\mathrm{P}<0.001^{*}$ \\
\hline Mean shortening of operated limb (cms) & $1.06 \pm 0.38$ & $1.56 \pm 0.43$ & $\mathrm{P}<0.001^{*}$ \\
\hline
\end{tabular}

Table 3: Comparison of functional outcome within and between the two groups.

\begin{tabular}{|c|c|c|c|}
\hline & PFN (n=32) & DHS (n=31) & $\begin{array}{l}\text { Between groups } \\
\text { (Kruskal-Wallis test) }\end{array}$ \\
\hline Pain & Median (SD) & Median (SD) & \\
\hline 6 weeks & $20(8.3)$ & $10(7.1)$ & $0.001 *$ \\
\hline 3 months & $30(4.5)$ & $30(5.8)$ & $0.009 *$ \\
\hline 6 months & $35(3.4)$ & $35(2.3)$ & 0.057 \\
\hline Within groups (Freidman's test ) & $* \mathrm{P}<0.001$ & $* \mathrm{P}<0.001$ & \\
\hline \multicolumn{4}{|l|}{ Functional ability } \\
\hline 6 weeks & $8(3.8)$ & $7(3.5)$ & 0.428 \\
\hline 3 months & $17(5.6)$ & $16(4.2)$ & 0.061 \\
\hline 6 months & $25(3.8)$ & $22(3.9)$ & 0.263 \\
\hline Within groups (Freidman's test ) & $* \mathrm{P}<0.001$ & $* \mathrm{P}<0.001$ & \\
\hline \multicolumn{4}{|l|}{ Gait } \\
\hline 6 weeks & $1(3.0)$ & $1(1.8)$ & $0.002 *$ \\
\hline 3 months & $9(2.8)$ & $6(2.8)$ & $0.006^{*}$ \\
\hline 6 months & $12(1.9)$ & $9(2.0)$ & $0.012 *$ \\
\hline Within groups (Freidman's test ) & $* \mathrm{P}<0.001$ & $* \mathrm{P}<0.001$ & \\
\hline \multicolumn{4}{|l|}{ Anatomic Assessment } \\
\hline 6 weeks & $15(1.3)$ & $13(3.0)$ & 0.073 \\
\hline 3 months & $15(0.6)$ & $15(0.4)$ & 0.543 \\
\hline 6 months & $15(0.5)$ & $15(0.4)$ & 0.056 \\
\hline Within groups (Freidman's test ) & $* \mathrm{P}<0.001$ & $* \mathrm{P}<0.001$ & \\
\hline
\end{tabular}




\begin{tabular}{|llll|}
\hline Total Score & & & \\
\hline 6 weeks & $50.5(13.0)$ & $36(11.5)$ & $0.001 *$ \\
\hline 3 months & $75(11.1)$ & $66(10.5)$ & $0.002 *$ \\
\hline 6 months & $88(8.2)$ & $84(6.4)$ & $0.049 *$ \\
\hline Within groups (Freidman's test ) & $* \mathrm{P}<0.001$ & $* \mathrm{P}<0.001$ & \\
\hline
\end{tabular}

significant

Mean duration of surgery in PFN group was $60.25 \pm 10.24$ minute and $90.78 \pm 8.04$ minute in DHS group. Mean duration after which patient started weight bearing was $4.96 \pm 1.63$ week in PFN group and $8.03 \pm 2.26$ week in DHS group (Table 2). One patient with DHS died 2 months after surgery because of cardiovascular problem and was not included in the final assessment of the functional outcome. One patient in DHS group had superficial wound infection which healed with regular dressing and antibiotic therapy. One patient developed palsy of common peronial nerve after operating with DHS for which foot drop splint was given at the time of mobilisation. Mean shortening of the affected limb in DHS group was $1.55 \pm 0.49 \mathrm{~cm}$ as compared with $1.21 \pm 0.74 \mathrm{~cm}$ in PFN group (Table 2).

Three patients in the PFN group and six patients in the DHS group complained of pain in the operated hip region up to 6 months post operatively. Difference in functional outcome between the groups was seen in post-operative pain and gait components of the Larson's chart 2 score. Values in functional ability and anatomic assessment were not significant. Within the groups all the components of Larson's hip evaluation chart 2 were significant when compared at 6 weeks and 3 months. Total score of all four components of scoring system were significant between the two groups at 6 weeks, 3 months and 6 months (Table 3).

\section{DISCUSSION}

These days surgical fixation is the preferred mode of treatment option for unstable trochanteric fracture as it decreases the complications and morbidity associated with these fractures. DHS being the implant of choice in the surgical management of trochanteric fractures has given good results in stable fractures as compared to unstable trochanteric fractures. ${ }^{5}$ PFN being an intramedullary device gives better fixation of the trochanteric fracture by restoring the anatomy of the hip. ${ }^{6}$ PFN gives biomechanically stable construct allowing early weight bearing in unstable trochanteric fractures. ${ }^{7,8}$

Many studies recommended PFN for the surgical treatment of unstable trochanteric fractures as controlled compression of fracture occurs without rotational malalignment of the fracture fragments. ${ }^{9-11}$ The patients treated with PFN were able to walk earlier than those treated by DHS as reported by many studies. ${ }^{6,812}$ This finding was also seen in our study.

Unstable trochanteric fractures treated with DHS were associated with higher incidence of complications. ${ }^{9}$
Fractures treated with DHS results in greater impaction of the fracture with shortening of the femoral neck. ${ }^{6}$ Many studies reported longer duration of surgery and greater blood loss in DHS group. ${ }^{6,13,14}$ In our study shortening was more and weight bearing was started late in patients treated with DHS as compared to patients treated with PFN. DHS is associated with a higher incidence of complications when used in unstable trochanteric fractures. ${ }^{9}$

Functional score in patients treated with PFN was better than DHS in the first 3 months. ${ }^{15}$ Patients who were treated by PFN restored walking ability earlier as compared to those treated by DHS. ${ }^{6}$ Our study results were similar to above study findings. Restoration of function is better with PFN when compared with DHS. In our study Functional outcome was better in patients treated with PFN compared to the patients treated with DHS in the initial 6 months of postoperative period. The follow up period in this study ranged from 6 months to 18 months because of the non-compliance from the patient side for subsequent follow up. Patients were reluctant to come for follow up once they did not experience pain in the operated hip and have started walking independently.

\section{CONCLUSION}

Our study results suggest PFN as better implant for the treatment of unstable trochanteric fractures when compared to DHS. PFN being an intramedullary implant gives stable fixation to these types of fractures and helps in earlier mobilisation of patients thus, minimizing the complications associated with unstable trochanteric fractures. Further studies with longer duration of follow up are required to conclude on the long term outcome of this these implants in unstable trochanteric fractures.

\section{ACKNOWLEDGMENTS}

Authors would like to thank Dr Gautham M S, MD (Community Medicine) and Dr Panchasheela S R, MD (Community Medicine) for statistical analysis of the data.

Funding: No funding sources

Conflict of interest: None declared

Ethical approval: The study was approved by the institutional ethics committee

\section{REFERENCES}

1. Schipper B, Marti RK, Werken CVD. Unstable trochanteric femoral fractures: extramedullary or intramedullary fixation. Injury. 2004;35(2):142-51. 
2. Kouvidis GK, Sommers MB, Giannoudis PV, Katonis PG, Bottlang M. Comparison of migration behavior between single and dual lag screw implants for intertrochanteric fracture fixation. J Orthopaedic Surg Research. 2009:19450283.

3. Vidyadhara S, Rao SK. One and two femoral neck screws with intramedullary nails for unstable trochanteric fractures of femur in the elderlyRandomized clinical trial. Injury. 2007;38(7):80614.

4. Weinlein JC. Fractures and dislocations of the hip. In: Canale ST, Beaty JH, eds. Campbell's Operative Orthopaedics. $12^{\text {th }}$ ed. Elsevier Mosby;2013:27442748.

5. Agrawal N, Ashok T, Muhammad S, Mehra AK. Comparative study of the management of intertrochanteric fractures in the elderly: short proximal femoral nail vs dynamic hip screw. Sri Lanka J Surg. 2012;30(2):13-7.

6. Pajarinen J, Lindah J, Michelsson O. Pertrochanteric femoral fractures treated with a dynamic hip screw or a proximal femoral nail a randomised study comparing post-operative rehabilitation. J Bone Joint Surg Br. 2005;87:76-81.

7. Kamboj P, Siwach R, Kundu Z, Sangwan S, Walecha P, Singh R. Results of modified proximal femoral nail in peritrochanteric fractures in adults. Internet J Orthopedic Surg. 2007;6(2):1-6.

8. Yassari AG, Langstaff RJ, Jones JWM, Lami AM. The AO/ASIF proximal femoral nail (PFN) for the treatment of unstable trochanteric femoral fracture. Injury. 2002;33:395-9.
9. Klinger HM, Baums MH, Ecketr M, Neugebauer R. A comparative study of unstable per and intertrochanteric femoral fractures treated with DHS and trochanteric buttress plate vs. proximal femoral nail. Zentralbl Chir. 2005;130(4):301-6.

10. Min, Woo KK, Shin YK, Tae K, Lee KB, Cho, et al. Proximal femoral nail for the treatment of reverse obliquity intertrochanteric fractures compared with gamma nail. Journal Trauma. 2007;63(5):1054-60.

11. Sommers MB, Roth C, Hall H. A laboratory model to evaluate cut out resistance of implants for pertrochanteric fracture fixation. J Orthop Trauma. 2004;18:361-8.

12. Harrington $P$, Nihal A, Singhania AK. Intramedullary hip screw versus sliding hip screw for intertrochanteric femoral fractures in the elderly. Injury. 2002;33:23-8.

13. Taeger G, Schmid C, Zettl R, Schweiberer L, Nast KD. Stable and unstable pertrochanteric femoral fractures differentiated indications for the dynamic hip screw. Der Unfallchirurg. 2000;103(9):741-8.

14. Muzaffar N, Malik AR, Shikari AA. Comparison between proximal femoral nail and locking compression plate-dynamic hip screw devices in unstable intertrochanteric fracture - which is better? J Orthopedics. 2013;5(1):11.

15. Myderrizi N. Proximal femoral nailing is better choice in treatment of intertrochanteric fracture in elderly people. Int Surg J. 2016;3(2):781-5.

Cite this article as: Mayi SC, Shah S, Jidgekar SR, Kulkarni A. Randomized comparative study to evaluate the role of PFN and DHS in unstable trochanteric fractures. Int J Res Orthop 2016;2:75-9. 